\title{
Hepatic Adenomas: Analysis of Sex Steroid Receptor Status and the Wnt Signaling Pathway
}

\author{
Michael Torbenson, M.D., Jae-Hyuk Lee, M.D., Ph.D., Michael Choti, M.D., Wesley Gage, B.A., \\ Susan C. Abraham, M.D., Elizabeth Montgomery, M.D., John Boitnott, M.D., Tsung-Teh Wu, M.D., Ph.D. \\ Division of Gastrointestinal/Liver Pathology, Department of Pathology (MT, J-HL, SCA, EM, JB, T-TW); \\ Department of Surgery (MC); and Department of Medical Oncology (WG), The Johns Hopkins University \\ School of Medicine, Baltimore, Maryland
}

Hepatic adenomas are strongly linked to excess hormonal exposure, but little else is known about their pathogenesis. The Wnt signaling pathway, which is activated in both hepatocellular carcinomas and hepatoblastomas, has not been studied in hepatic adenomas. Fifteen hepatic adenomas were studied by immunohistochemistry for estrogen, progesterone, and androgen receptors (ER, PR, AR, respectively) and correlated with the results of immunostaining for $\beta$-catenin. Direct sequencing was performed to look for mutations in key genes involved in the Wnt signaling pathway: Exon 3 of $\beta$-catenin encompassing the glycogen synthase kinase $3 \beta$ (GSK-3 $\beta$ ) phosphorylation region and the mutational cluster region of the adenomatosis polyposis coli protein (APC). Analysis for loss of heterozygosity (LOH) at chromosome $5 q$ was also performed. Immunostaining for both ER and PR was present in 11/15 (73\%) adenomas, and staining with one hormone receptor was positively associated with staining for the other receptor. AR positivity was present in $3 / 15$ cases. Nuclear accumulation of $\beta$-catenin was present in $7 / 15(46 \%)$ of adenomas, indicating activation of the Wnt signaling pathway. However, no $\beta$-catenin mutations, no APC mutations in the mutational cluster region, and no $5 \mathrm{q}$ LOH were detected. Two APC polymorphisms of unknown significance were seen. No clear association between $\beta$-catenin nuclear accumulation and hormone receptor positivity was discerned. Activation of the Wnt signaling pathway appears to be important in a subset of hepatic adenomas but does not result from common $\beta$-catenin or APC muta-

Copyright (C) 2002 by The United States and Canadian Academy of Pathology, Inc.

VOL. 15, NO. 3, P. 189, 2002 Printed in the U.S.A.

Date of acceptance: November 19, 2001

Tsung-Teh Wu, M.D., Ph.D., is now at the Department of Pathology, University of Texas M.D. Anderson Cancer Center, Houston, Texas.

Address reprint requests to: Michael Torbenson, M.D., Department of Pathology, Ross Building, Room 632, The Johns Hopkins University School of Medicine, 720 Rutland Avenue, Baltimore, MD 21205-2196; e-mail: mtorben@pds.path.jhu.edu; fax: 410-614-9011. tions and does not appear to be directly linked to hormonal receptor status.

KEY WORDS: APC, $\beta$-catenin, Estrogen, GSK-3 $\beta$, Hepatic adenoma, Immunohistochemistry, Progesterone.

Mod Pathol 2002;15(3):189-196

Hepatic adenomas are benign hepatocellular neoplasms that are seen in noncirrhotic livers. Almost all hepatic adenomas arise in one of three clinical settings: (1) reproductive age women, usually with a history of oral contraceptive pill (OCP) therapy (1), (2) excess androgen exposure such as in patients on androgen steroid therapy for Fanconi's anemia (2, 3 ), and (3) glycogen storage disease Types I and III (4). Rare cases of hepatic adenomas have also been reported in a number of other clinical settings. Overall, hepatic adenomas are most commonly found in women with a history of OCP use, underscoring the importance of hormonal excess in the development of adenomas, a causal role that has been strongly supported by epidemiological studies (5). However, the data on sex steroid receptors in hepatic adenomas have been inconsistent, with studies reporting both the presence and absence of receptors using both chemical $(6,7)$ and immunohistochemical analysis $(8,9)$. The largest reported study using immunohistochemistry found sex hormone receptors in only one third of adenomas (8).

Beyond the link with excess sex hormones, very little is known about the pathogenesis of hepatic adenomas. One candidate pathway is the Wnt signaling pathway, which tightly regulates $\beta$-catenin levels through a degradation pathway in which adenomatosis polyposis coli (APC) and Axin I proteins bind to $\beta$-catenin, leading to its phosphorylation by GSK-3 $\beta$ and degradation through the proteosome system. When the Wnt signaling pathway is activated, $\beta$-catenin accumulates in the nucleus, where it can be detected by immunohistochemical staining. Multiple separate lines of evidence suggest a 
possible role for the Wnt signaling pathway in the pathogenesis of hepatic adenomas. First, mutations in genes encoding key proteins in the Wnt signaling pathway have been described in other hepatic neoplasms, all of which lead to constitutive activation of the Wnt signaling pathway: $\beta$-catenin $(10-12)$ and $\operatorname{APC}(13,14)$ in hepatoblastomas; $\beta$-catenin (15-22) and Axin I (23) in hepatocellular carcinomas. Secondly, rare hepatic adenomas have been reported in children with germline APC mutations $(14,24)$. Finally sex steroid hormones including estrogen, progesterone, and androgens have all been shown to affect cellular levels of $\beta$-catenin in other organ systems (25-27).

The first goal of this study was to evaluate hepatic adenomas for activation of the Wnt signaling pathway as evidenced by nuclear accumulation of $\beta$-catenin, followed by examination of the two genes of the Wnt signaling pathway most commonly mutated in other hepatocellular neoplasms through direct sequencing of Exon 3 of $\beta$-catenin and the mutational cluster region APC. The second goal of this study was to confirm the presence of sex steroid receptors in hepatic adenomas using immunohistochemistry and to explore any relationship between activation of the Wnt signaling pathway and the presence of sex steroid receptors.

\section{MATERIALS AND METHODS}

\section{Case Selection}

Fifteen cases of hepatic adenomas resected between 1991 to 2001 were retrieved from the archives of the Johns Hopkins Department of Pathology under appropriate institutional review board protocol. Cases were selected to include only women with no evidence for familial adenomatosis polyposis or glycogen storage disease. All of the women were premenopausal, with the exception of one patient with a history of OCP exposure who had underwent a hysterectomy and bilateral salpingo-oophorectomy and was on estrogen replacement therapy at the time of resection. Histological sections were obtained from formalin-fixed, paraffin-embedded tissues, and all cases were retrospectively reviewed to confirm the diagnosis of hepatic adenoma.

\section{Immunohistochemistry}

The following stains were performed after steam antigen retrieval: $\beta$-catenin (1:500 dilution, Becton Dickinson Transduction Laboratories, Lexington, KY), estrogen receptor (1:40 dilution, DAKO, Carpinteria, CA), progesterone receptor (1:60 dilution, DAKO), androgen receptor (1:40 dilution, DAKO). The percentage of hepatocyte nuclei with positive staining was scored on a scale of 0 to $4(0=$ none or only exceptionally rare positive nuclei, $1=$ 1 to $25 \%$ positive nuclei, $2=26$ to $50 \%$ positive nuclei, $3=51$ to $75 \%$ positive nuclei, and $4=76$ to $100 \%$ positive nuclei. In cases with patchy positivity, the percentage of positive nuclei in the positive patches was scored.

\section{Mutational Analyses}

DNA was extracted by microdissection of $5-\mu \mathrm{m}-$ thick, hematoxylin and eosin-stained slides from formalin-fixed, paraffin-embedded tissue. Both neoplastic and nonneoplastic liver (available in all but one case) were separately microdissected, and genomic DNA was extracted as described elsewhere (28).

Oligonucleotide primers (Table 1) were selected to amplify Exon 3 of $\beta$-catenin, which encompasses the region for GSK- $3 \beta$ phosphorylation, and the mutational cluster region of the APC gene. Polymerase chain reaction (PCR) was performed in 35- $\mu$ L volumes using a PCR master mix (Boehringer Mannheim, Mannheim, Germany) with $1 \mu \mathrm{M}$ of both $5^{\prime}$ and 3' oligonucleotides for 40 cycles. For $\beta$-catenin, the following conditions were used: $94^{\circ}$ $\mathrm{C}$ for 1 minute, $58^{\circ} \mathrm{C}$ for 1 minute, and $72^{\circ} \mathrm{C}$ for 1

TABLE 1. Primers Used in Polymerase Chain Reaction (PCR) Amplification and Sequencing

\begin{tabular}{|c|c|c|}
\hline Gene & PCR Amplification & Sequencing \\
\hline \multicolumn{3}{|l|}{$\beta$-catenin } \\
\hline Forward & 5'-ATGGAACCAGACAGAGGGGC-3' & 5'-AAAGCGGCTGTTAGTCACTTGG-3' \\
\hline Reverse & 5'-GCTACTTGTTCTTGAGTGAAG-3' & 5'-CCTGTTCCCACTCATACAGG-3' \\
\hline \multicolumn{3}{|l|}{$\beta$-catenin, large deletions } \\
\hline Forward & 5'-CCAGCGTGGACAATGGCTAC-3' & NA \\
\hline Reverse & 5'-TGAGCTCGAGTCATTGCATAC-3' & NA \\
\hline \multicolumn{3}{|c|}{ s } \\
\hline A-forward (Codons 1260 to 1359) & 5'-CAGACTTATTGTGTAGAAGA-3' & Same as for PCR amplification \\
\hline A-reverse & 5' -CTCCTGAAGAAAATTCAACA-3' & Same as for PCR amplification \\
\hline B-forward (Codons 1339 to 1436 ) & 5'-AGGGTTCTAGTTTATCTTCA-3' & Same as for PCR amplification \\
\hline B-reverse & 5' -TCTGCTTGGTGGCATGGTTT-3' & Same as for PCR amplification \\
\hline C-forward (Codons 1417 to 1516 ) & 5'-GGCATTATAAGCCCCAGTGA-3' & Same as for PCR amplification \\
\hline C-reverse & 5'-AAATGGCTCATCGAGGCTCA-3' & Same as for PCR amplification \\
\hline D-forward (Codons 1497 to 1596 ) & 5' -ACTCCAGATGGATTTTCTTG-3' & Same as for PCR amplification \\
\hline D-reverse & 5'-GGCTGGCTTTTTTGCTTTAC-3' & Same as for PCR amplification \\
\hline
\end{tabular}

NA, not available; APC, adenomatosis polyposis coli. 
minute. Frozen tissue was available in four cases, and a fragment spanning the entire length of Exon 3 was amplified to detect large interstitial deletions as described elsewhere (28). For APC, the following conditions were used for DNA amplification: $94^{\circ} \mathrm{C}$ for 1 minute, $55^{\circ} \mathrm{C}$ for 1 minute, and $68^{\circ} \mathrm{C}$ for 2 minutes. PCR products for both $\beta$-catenin and APC were then purified using shrimp alkaline phosphatase and exonuclease I (Amersham, Buckinghamshire, United Kingdom) and directly sequenced using internal primers for $\beta$-catenin and the same primers used for DNA amplification for APC with the SequiTherm Excel II DNA Sequencing Kit (Epicentre, Madison, WI), for both the sense and antisense directions.

\section{Allelic Loss on Chromosome $5 q$}

Loss of heterozygosity ( $\mathrm{LOH}$ ) on $5 \mathrm{q}$ was evaluated by PCR amplification of three microsatellite markers (D5S299, D5S346, D5S82) as described elsewhere (28). LOH was defined as disappearance or a reduction of $\geq 50 \%$ in the intensity of a heterozygous band.

\section{RESULTS}

\section{Clinical and Demographic Information}

The patients had an average age of $35 \pm 10$ (SD) years at the time of hepatic adenoma resection with the age range from 19 to 56 years. All patients were negative for hepatitis $\mathrm{B}$ and $\mathrm{C}$ infections. Clinical history was available for 14 women, 9 of whom had histories of OCP use. One of the women without a history of OCP use presented with metromenorrhagia associated with an ovarian neoplasm, and the hepatic adenoma was an incidental finding. In addition, one patient had a history of ongoing androgen therapy for Fanconi's anemia (Case 13). Serum $\alpha$-fetoprotein levels were available in 12 patients and were within normal limits for all.

\section{Gross and Histological Findings}

The adenomas were single lesions in 10 cases and were multiple in 5 cases. The tumors averaged $11 \pm$ 6 (SD) $\mathrm{cm}$ in diameter (range, 2 to $26 \mathrm{~cm}$ ). Histologically, the tumors were composed of blandappearing hepatocytes with loss of normal architectural patterns, including the absence of portal tracts and central veins and the presence of scattered aberrant vessels. Six of the cases had pseudocapsules of compressed fibrous tissue, often containing large, dilated, and tortuous vessels. The individual hepatocytes were organized into cords of one to two cells in thickness. No nuclear or cytological atypia was seen, with the exception of Case 13, a patient with a history of androgen therapy. Mitoses were exceptionally rare in each case, with no mitoses detected in any of the cases in 50 high-power fields $(400 \times)$.

\section{Immunohistochemical Results}

As shown in Table 2, 11/15 cases were positive for ER (73\%), $11 / 15$ for PR (73\%), and 3/15 for AR (20\%; Fig. 1). There was a positive correlation between immunostaining for ER and PR $(P=.03$; Fisher's exact test). In about half of the cases (5/11 ER, 4/11 PR), the staining was diffuse, with positive cells sprinkled somewhat uniformly throughout the tissue, whereas in the remaining cases, the staining was distinctly patchy (Table 3). In all but one of the cases, when the tumor was positive for sex hormone receptors, the nonneoplastic liver was also positive, though generally with a lower percentage of positive hepatocytes and never with a greater percentage of positivity. In a single case (No. 9), the tumor was positive for both ER and PR, but the nonneoplastic liver was negative. No cases were found in which the nonneoplastic liver was positive but tumor negative. These same observations also applied to $A R$, where a total of three adenomas showed a patchy distribution of positive hepatocytes.

Immunostains for $\beta$-catenin were positive in $7 / 15$ (46\%), 3 of which showed positive nuclei sprinkled throughout the neoplasm in a generally diffuse pattern, whereas the remaining 4 cases showed a patchy distribution (Fig. 2). In two of the cases with a patchy distribution (Cases 9 and 11), the foci of positive hepatocytes were rare and made up $<1 \%$ of the total hepatocytes. In the other two cases with a patchy distribution, the total percentage of positive hepatocytes was approximately $20 \%$ for each case. Six of the seven cases with $\beta$-catenin positivity were also positive for ER or PR $(P=.6$; Fisher's exact test). No clear geographic correlation between ER/PR staining and $\beta$-catenin could be detected, though this was often difficult to evaluate, in particular in the cases where positive cells were scattered throughout the neoplasm. In the one case in which the ER, PR, and $\beta$-catenin all showed a patchy distribution, no clear geographical association was seen.

Two other interesting patterns of $\beta$-catenin positivity were seen. First, in case no. 13, foci of hepatocytes

TABLE 2. Estrogen Receptor (ER), Progesterone
$\begin{aligned} & \text { Receptor (PR), Androgen Receptor (AR), and } \beta \text {-catenin } \\
& \text { Immunostaining in Hepatic Adenomas and Normal Liver }\end{aligned}$
\begin{tabular}{ccc} 
Ammunostain & $\begin{array}{c}\text { Adenomas Positive } \\
(\%), N=15\end{array}$ & $\begin{array}{c}\text { Nonneoplastic Hepatocytes } \\
\text { Positive }(\%), N=14\end{array}$ \\
\hline ER & 73 & 71 \\
PR & 73 & 71 \\
AR & 20 & 20 \\
$\beta$-catenin & 46 & 13 \\
\hline
\end{tabular}




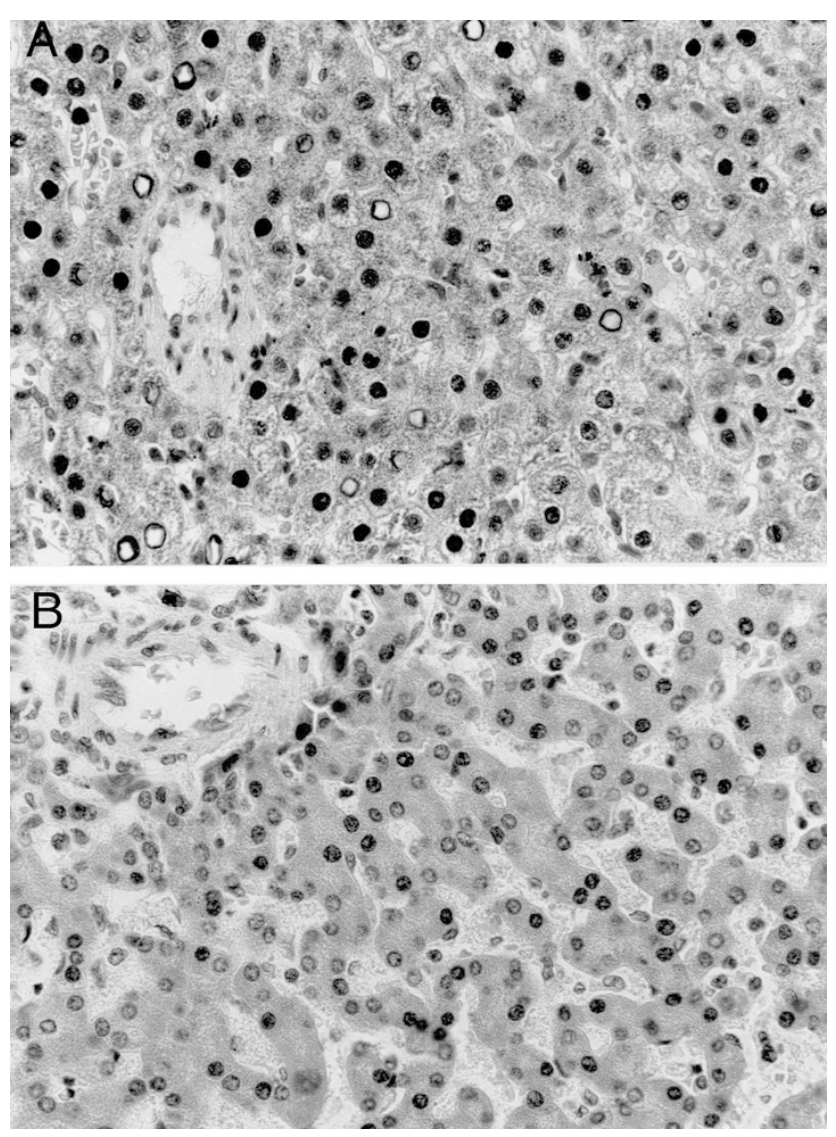

FIGURE 1. A hepatic adenoma showing strong nuclear staining for estrogen (A) and progesterone (B) receptors.

with atypia showed loss of the normal membranous staining of $\beta$-catenin with variable nuclear accumulation. Nuclear $\beta$-catenin accumulation was also evident in many of the adjacent neoplastic hepatocytes without atypia (Fig. 3). Secondly, nuclear $\beta$-catenin accumulation was noted focally in the adjacent, nonneoplastic hepatocytes in two cases (Cases 14 and 15), both of which showed ER and PR positivity in the same areas (Fig. 4).

\section{Mutational Analysis}

Direct sequencing of Exon 3 of $\beta$-catenin encompassing the GSK-3 $\beta$ phosphorylation region revealed no mutations. In addition, no large interstitial deletions were detected in the four cases studied. Sequencing of the mutational cluster region for APC showed no mutations. However, polymorphisms were detected in two cases, neither of which showed nuclear accumulation of $\beta$-catenin. The polymorphism in Case 2 was a T to A transversion at Codon 1442 and did not lead to a change in the amino acid. However, in Case 9, a base pair change in Codon 1454 did lead to a change in the amino acid sequence, from lysine to glutamine. The amino acid change was present in both the normal liver and adenoma and was interpreted as a poly- morphism. The patient had no clinical evidence for a colonic polyposis syndrome. No $5 \mathrm{q} \mathrm{LOH}$ was detected in any of the 12 informative cases.

\section{DISCUSSION}

Hepatic adenomas were exceptionally rare before the introduction of OCP therapy in the 1960s, and previous epidemiological studies have strongly linked OCPs to hepatic adenomas (5). Although newer formulations of OCPs appear to have a much lower risk for the development of hepatic adenomas (29), 11 of the cases in this series were resected in the last 5 years (between 1996 and 2001), underscoring the continued presence of these tumors as a clinical concern. Despite the strong causal association between adenomas and older formulations of OCP, the tissue link between ER or PR receptors and hepatic adenomas has been less clear. Early studies using biochemical methods led to mixed results $(6,7)$, although overall the weight of the evidence suggested that receptors were present. Two subsequent studies have been reported using immunohistochemistry and were again mixed, with one study reporting negative results (9) and the second reporting ER or PR receptors in one third of adenomas (8). In contrast to these reports, $73 \%$ of cases in this study were positive for ER or PR by immunohistochemistry. This discrepancy may be related to several factors. First, this study included only cases fitting the classical clinicopathological definition of bland neoplasms in reproductive-aged women who typically had histories of OCP use. In contrast, other studies have included hepatic neoplasms that fall outside of the classic historical definition of adenomas, for instance, including bland neoplasms in men with no history of excess hormonal exposure $(8,9)$. Second, only complete resections were included in this study, whereas others have included a mixture of resected adenomas, needle biopsies, and fine needle aspirates (8). Immunostaining for ER and PR can be patchy in many adenomas, as noted in this and other reports (8), and may have led to false negatives in specimens that were biopsied or aspirated. In fact, the truepositive rate may be even higher than detected in this study, as only one slide per resected specimen was stained. ER and PR receptors were also present, though typically to a lower degree, in the nonneoplastic livers in 10/11 cases in which the adenomas were positive, suggesting that the entire livers in these patients were potentially hormonally responsive. Finally, nuclear ER and PR staining was positively correlated, with most cases showing positivity for both hormone receptors.

A total of seven adenomas (46\%) showed nuclear $\beta$-catenin accumulation, indicating activation of 
TABLE 3. $\beta$-Catenin Immunostaining Results and $\beta$-Catenin and APC Mutational Analysis Findings

\begin{tabular}{|c|c|c|c|c|c|c|}
\hline \multirow{2}{*}{$\begin{array}{l}\text { Case } \\
\text { No. }\end{array}$} & \multicolumn{4}{|c|}{ Degree of Immunostaining $^{a}$} & \multicolumn{2}{|c|}{ Mutation Analysis } \\
\hline & ER & PR & $\mathrm{AR}$ & $\beta$-Catenin & $\begin{array}{c}\beta- \\
\text { Catenin }\end{array}$ & APC \\
\hline 1 & $1 d$ & $1 d$ & 0 & 0 & Wild type & Wild type \\
\hline 2 & $3 d$ & $1 p$ & $1 \mathrm{p}$ & 0 & Wild type & $\begin{array}{l}4344 \text {, T to A; } 1442 \text {, CCT to CCA; } \\
\text { no amino acid change }\end{array}$ \\
\hline 3 & $1 d$ & $2 \mathrm{~d}$ & 0 & 0 & Wild type & Wild type \\
\hline 4 & 0 & $1 d$ & 0 & 0 & Wild type & Wild type \\
\hline 5 & $1 \mathrm{p}$ & 0 & $1 \mathrm{p}$ & 0 & Wild type & Wild type \\
\hline 6 & 0 & 0 & $1 \mathrm{p}$ & 0 & Wild type & Wild type \\
\hline 7 & 0 & 0 & 0 & 0 & Wild type & Wild type \\
\hline 8 & $1 d$ & $2 \mathrm{~d}$ & 0 & $1 \mathrm{p}$ & Wild type & Wild type \\
\hline 9 & $2 p$ & $2 p$ & 0 & 0 & Wild type & $\begin{array}{l}\text { 4378, A to G; } 1454 \text {, AAA to GAA; } \\
\text { lys } \rightarrow \text { glu }\end{array}$ \\
\hline 10 & 0 & 0 & 0 & $3 d$ & Wild type & Wild type \\
\hline 11 & $1 \mathrm{p}$ & $1 \mathrm{p}$ & 0 & $1 \mathrm{p}$ & Wild type & Wild type \\
\hline 12 & $1 d$ & $2 \mathrm{~d}$ & 0 & $2 \mathrm{p}$ & Wild type & Wild type \\
\hline 13 & $1 \mathrm{p}$ & $1 d$ & 0 & $2 \mathrm{~d}$ & Wild type & Wild type \\
\hline 14 & $2 \mathrm{p}$ & $1 \mathrm{p}$ & 0 & $1 d$ & Wild type & Wild type \\
\hline 15 & $1 \mathrm{p}$ & $2 \mathrm{~d}$ & 0 & $2 \mathrm{p}$ & Wild type & Wild type \\
\hline
\end{tabular}

ER, estrogen receptor; PR, progesterone receptor; AR, androgen receptor; APC, adenomatosis polyposis coli.

${ }^{a}$ Immunostain scoring: $0=$ no or only exceptionally rare positive nuclei; $1=1-25 \%$ positive nuclei, $2=26-50 \%$ positive nuclei, $3=51-75 \%$ positive nuclei, $4=76 \%-100 \%$ positive nuclei; $\mathrm{d}=$ diffuse staining; $\mathrm{p}=$ patchy staining.

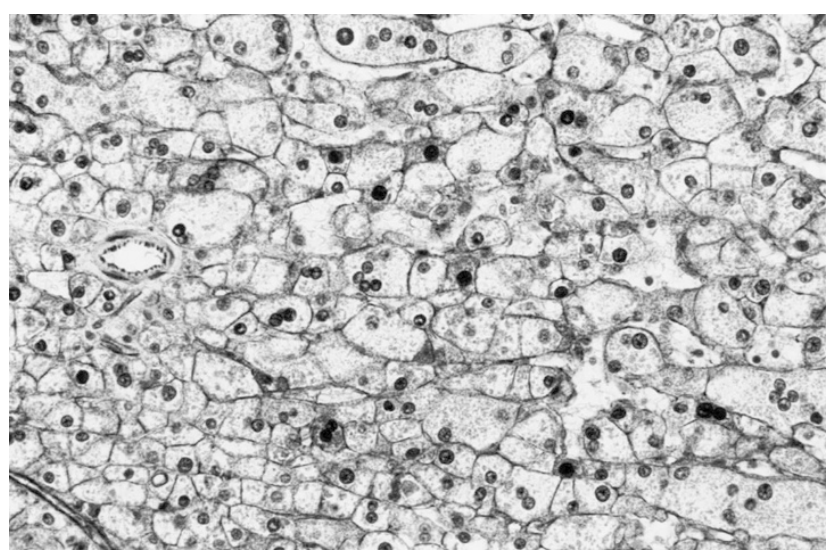

FIGURE 2. A hepatic adenoma showing nuclear accumulation of $\beta$-catenin. Membranous staining is also present.

the Wnt signaling pathway. However, no $\beta$-catenin or APC mutations were detected. These results suggest that activation of the Wnt signaling pathway is important in a subset of hepatic adenomas but occurs through a different mechanism than that seen most commonly in other hepatic neoplasms. In fact, all three types of hepatocellular neoplasms appear to show activation of the Wnt signaling pathway through somewhat different pathways (Table 4). First, in hepatoblastomas, the Wnt signaling pathway appears to be primarily activated through deletions and missense mutations in $\beta$-catenin, with some studies also indicating a role for truncating and missense mutations in APC (1013, 30-32). In contrast, hepatocellular carcinomas show predominately missense mutations in $\beta$-catenin, with only rare deletions and no evidence for APC mutations (15-22, 33). Axin I mutations have also been reported in hepatocellular carcino-

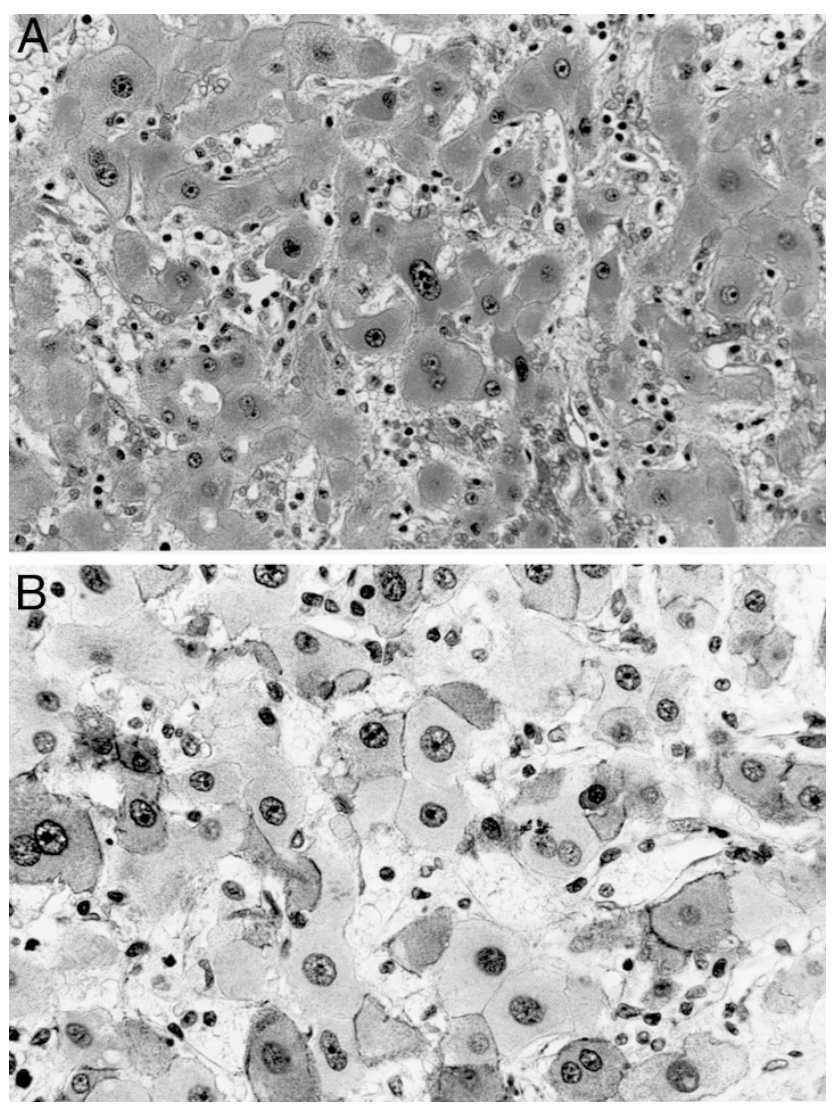

FIGURE 3. The hepatic adenoma in Patient 13, who had a history of androgen therapy, showed mild cytological atypia (A). $\beta$-catenin immunostaining (B) in this same region shows that the neoplastic hepatocytes with atypia have lost their normal membranous staining pattern and also show variable nuclear accumulation.

mas (23) but have not been studied in either hepatoblastomas or adenomas. Finally, the mechanism of activation of the Wnt signaling pathway in hepatic adenomas remains unclear. One possibility is 


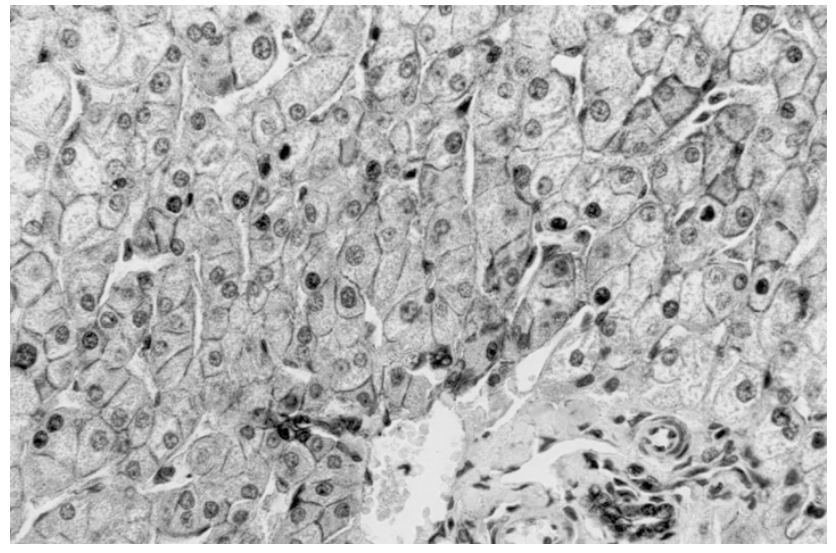

FIGURE 4. In two cases, occasional nonneoplastic hepatocytes showed nuclear $\beta$-catenin accumulation. The normal hepatocytes typically showed a membranous staining pattern for $\beta$-catenin. A small bile duct with a membranous staining can also be seen in the portal tract in the lower right.

that large interstitial deletions in $\beta$-catenin were present in those cases that could not be analyzed for large deletions because of the lack of frozen tissue. Hsu et al., in a study focused on hepatocellular carcinomas, also mentioned that large interstitial deletions of $\beta$-catenin were detected in two of five hepatic adenomas (21). Mutations in the Axin I gene or other genes involved in the Wnt signaling pathway may also have been involved in some of the cases in this study. Although the entire APC gene was not sequenced in this study, APC mutations appear unlikely to play a significant role because no mutations were detected by direct sequencing of the mutational cluster region and no LOH was seen on chromosome 5q. Case 9 did show an APC transition in codon 1454 that resulted in an amino acid change, but this is of unknown significance because this change was also present in the patient's normal tissue. Searching the Thierry Soussi database of APC mutations (http:/perso.curie.fr/Thierry.Soussi/APC.html) revealed this codon to be occasionally affected by insertions and deletions, but no missense mutations were reported. Case 2 showed a polymorphism at codon 1442 resulting from a $\mathrm{T}$ to $\mathrm{A}$ transversion that did not result in an amino acid change. This polymorphism has been linked to Portuguese populations (34) and is also of unknown clinical significance. The Thierry Soussi database also has one reported case of a similar mutation in a benign sporadic colorectal adenoma.

Two of the cases in this study showed focal $\beta$-catenin nuclear accumulation in nonneoplastic hepatocytes. $\beta$-catenin immunostaining has been largely reported in the setting of hepatocellular carcinomas, and nuclear positivity in the normal liver tissue adjacent to hepatocellular carcinomas has not been previously reported to our knowledge. However, nuclear accumulation of $\beta$-catenin in non-neoplastic liver has been recently described in a rat model of liver regeneration, in which nuclear accumulation was detected at 5 minutes after hepatectomy in 100\% of hepatocytes by immunofluorescence. The nuclear $\beta$-catenin rapidly disappeared but was detectable for up to 48 hours in a small percentage of hepatocytes (35). These investigators also reported nuclear $\beta$-catenin positivity in cells with mitotic figures. Thus, the Wnt signaling pathway clearly plays an important and tightly regulated role in normal liver regeneration, and rare foci of nuclear $\beta$-catenin accumulation in normal hepatocytes are likely to be physiological. In contrast, the overexpression of $\beta$-catenin seen in the hepatic adenomas is unlikely to be physiological, as the degree of positivity was greater than could be accounted for by proliferation because the hepatic adenomas in this study showed a very low proliferative rate. Taken together, the combined results from this study and the studies discussed above suggest that the Wnt signaling pathway is important in normal liver regeneration and that abnormal activation of the Wnt signaling pathway plays an important role in a significant subset of all hepatocellular neoplasms that have been studied to date, though apparently through different mechanisms of activation.

The relationship between ER and PR staining and $\beta$-catenin positivity in hepatic adenomas is unclear. Although six of seven cases with $\beta$-catenin staining were also ER/PR positive, no statistical association was present and no obvious geographical correlation was discerned. Nevertheless, in other tissues, estrogen and progesterone have been shown to reg-

TABLE 4. Hepatocellular Neoplasms with Evidence for Activation of the Wnt Signaling Pathway by Nuclear $\beta$-Catenin Immunostaining and for $\beta$-Catenin, APC, and Axin I Mutations

\begin{tabular}{lcccc}
\hline \multicolumn{1}{c}{ Neoplasm } & $\begin{array}{c}\text { Nuclear } \beta \text {-Catenin } \\
\text { Staining, } \%(N)\end{array}$ & $\begin{array}{c}\text { Exon } 3 \beta \text {-Catenin Mutations, } \%(N) \\
\text { breakdown] }\end{array}$ & $\begin{array}{c}\text { APC Mutations, } \\
\%(N)\end{array}$ & $\begin{array}{c}\text { Axin I Mutations, } \\
\%(N)\end{array}$ \\
\hline Hepatoblastoma $^{a}$ & $78(65)$ & $\begin{array}{c}52(177)[33 \% \text { deletions, } 19 \% \text { point } \\
\text { mutations }]\end{array}$ & $12(168)$ & NA \\
Hepatocellular carcinoma $^{b}$ & $32(684)$ & $\begin{array}{c}17(1183)[2 \% \text { deletions, } 15 \% \text { point } \\
\text { mutations }]\end{array}$ & $0(68)$ & $7(237)$ \\
Hepatic adenoma & $47(15)$ & $0(15)$ & $0(15)$ & NA \\
\hline
\end{tabular}

Results are pooled from multiple representative studies in the literature and shown as weighted average percentage positive. APC, adenomatosis polyposis coli; NA, not available.

${ }^{a}$ See References 10-13, 30-32.

${ }^{b}$ See References 15-23, 33, 38. 
ulate cytoplasmic and nuclear levels of $\beta$-catenin (25-27) and our results do not exclude an association. It is also of interest to note that a number of earlier studies on liver regeneration reported an important role for estrogens $(36,37)$.

In conclusion, the Wnt signaling pathway probably is activated in a subset of hepatic adenomas through a mechanism other than $\beta$-catenin or APC gene mutations. ER and PR receptors can be detected in a majority of hepatic adenomas, though the staining pattern is often patchy. No correlation between $\beta$-catenin nuclear accumulation and ER/PR staining was detected. This study focused solely on hepatic adenomas arising in reproductive-aged women, most of whom had documented histories of OCP use. Hepatic adenomas arising in other settings were not studied, and further analysis would be required before extending these findings to such cases. [38]

\section{REFERENCES}

1. Reddy KR, Kligerman S, Levi J, Livingstone A, Molina E, Franceschi D, et al. Benign and solid tumors of the liver: relationship to sex, age, size of tumors, and outcome. Am Surg 2001;67:173-8.

2. Nakao A, Sakagami K, Nakata Y, Komazawa K, Amimoto T, Nakashima $\mathrm{K}$, et al. Multiple hepatic adenomas caused by long-term administration of androgenic steroids for aplastic anemia in association with familial adenomatous polyposis. J Gastroenterol 2000;35:557-62.

3. Touraine RL, Bertrand Y, Foray P, Gilly J, Philippe N. Hepatic tumours during androgen therapy in Fanconi anaemia. Eur J Pediatr 1993;152:691-3.

4. Labrune P, Trioche P, Duvaltier I, Chevalier P, Odievre M. Hepatocellular adenomas in glycogen storage disease type I and III: a series of 43 patients and review of the literature. J Pediatr Gastroenterol Nutr 1997;24:276-9.

5. Rosenberg L. The risk of liver neoplasia in relation to combined oral contraceptive use. Contraception 1991;43:643-52.

6. Porter LE, Elm MS, Van Thiel DH, Eagon PK. Hepatic estrogen receptor in human liver disease. Gastroenterology 1987; 92:735-45.

7. Carbone A, Vecchio FM. Presence of cytoplasmic progesterone receptors in hepatic adenomas. A report of two cases. Am J Clin Pathol 1986;85:325-9.

8. Cohen C, Lawson D, DeRose PB. Sex and androgenic steroid receptor expression in hepatic adenomas. Hum Pathol 1998; 29:1428-32.

9. Masood S, West AB, Barwick KW. Expression of steroid hormone receptors in benign hepatic tumors. An immunocytochemical study. Arch Pathol Lab Med 1992;116:1355-9.

10. Jeng YM, Wu MZ, Mao TL, Chang MH, Hsu HC. Somatic mutations of beta-catenin play a crucial role in the tumorigenesis of sporadic hepatoblastoma. Cancer Lett 2000;152: $45-51$.

11. Koch A, Denkhaus D, Albrecht S, Leuschner I, von Schweinitz D, Pietsch T. Childhood hepatoblastomas frequently carry a mutated degradation targeting box of the betacatenin gene. Cancer Res 1999;59:269-73.

12. Wei Y, Fabre M, Branchereau S, Gauthier F, Perilongo G, Buendia MA. Activation of beta-catenin in epithelial and mesenchymal hepatoblastomas. Oncogene 2000;19:498504 .
13. Oda H, Imai Y, Nakatsuru Y, Hata J, Ishikawa T. Somatic mutations of the APC gene in sporadic hepatoblastomas. Cancer Res 1996;56:3320-3.

14. Bala S, Wunsch PH, Ballhausen WG. Childhood hepatocellular adenoma in familial adenomatous polyposis: mutations in adenomatous polyposis coli gene and p53. Gastroenterology 1997;112:919-22.

15. Nhieu JT, Renard CA, Wei Y, Cherqui D, Zafrani ES, Buendia MA. Nuclear accumulation of mutated beta-catenin in hepatocellular carcinoma is associated with increased cell proliferation. Am J Pathol 1999;155:703-10.

16. Terris B, Pineau P, Bregeaud L, Valla D, Belghiti J, Tiollais P, et al. Close correlation between beta-catenin gene alterations and nuclear accumulation of the protein in human hepatocellular carcinomas. Oncogene 1999;18:6583-8.

17. Miyoshi Y, Iwao K, Nagasawa Y, Aihara T, Sasaki Y, Imaoka S, et al. Activation of the beta-catenin gene in primary hepatocellular carcinomas by somatic alterations involving exon 3. Cancer Res 1998;58:2524-7.

18. Mao TL, Chu JS, Jeng YM, Lai PL, Hsu HC. Expression of mutant nuclear beta-catenin correlates with non-invasive hepatocellular carcinoma, absence of portal vein spread, and good prognosis. J Pathol 2001;193:95-101.

19. Legoix P, Bluteau O, Bayer J, Perret C, Balabaud C, Belghiti J, et al. Beta-catenin mutations in hepatocellular carcinoma correlate with a low rate of loss of heterozygosity. Oncogene 1999;18:4044-6.

20. Huang H, Fujii H, Sankila A, Mahler-Araujo BM, Matsuda M, Cathomas G, et al. Beta-catenin mutations are frequent in human hepatocellular carcinomas associated with hepatitis C virus infection. Am J Pathol 1999;155:1795-801.

21. Hsu HC, Jeng YM, Mao TL, Chu JS, Lai PL, Peng SY. Betacatenin mutations are associated with a subset of low-stage hepatocellular carcinoma negative for hepatitis B virus and with favorable prognosis. Am J Pathol 2000;157:763-70.

22. de La Coste A, Romagnolo B, Billuart P, Renard CA, Buendia MA, Soubrane O, et al. Somatic mutations of the betacatenin gene are frequent in mouse and human hepatocellular carcinomas. Proc Natl Acad Sci U S A 1998;95:8847-51.

23. Satoh S, Daigo Y, Furukawa Y, Kato T, Miwa N, Nishiwaki T, et al. AXIN1 mutations in hepatocellular carcinomas, and growth suppression in cancer cells by virus-mediated transfer of AXIN1. Nat Genet 2000;24:245-50.

24. Giardiello FM, Petersen GM, Brensinger JD, Luce MC, Cayouette MC, Bacon J, et al. Hepatoblastoma and APC gene mutation in familial adenomatous polyposis. Gut 1996;39: 867-9.

25. Chen GT, Getsios S, MacCalman CD. Progesterone regulates beta-catenin mRNA levels in human endometrial stromal cells in vitro. Endocrine 1998;9:263-7.

26. Truica CI, Byers S, Gelmann EP. Beta-catenin affects androgen receptor transcriptional activity and ligand specificity. Cancer Res 2000;60:4709-13.

27. Eger A, Stockinger A, Schaffhauser B, Beug H, Foisner R. Epithelial mesenchymal transition by c-Fos estrogen receptor activation involves nuclear translocation of beta-catenin and upregulation of beta-catenin/lymphoid enhancer binding factor-1 transcriptional activity. J Cell Biol 2000;148:17388.

28. Wu TT, Watanabe T, Heitmiller R, Zahurak M, Forastiere AA, Hamilton SR. Genetic alterations in Barrett esophagus and adenocarcinomas of the esophagus and esophagogastric junction region. Am J Pathol 1998;153:287-94.

29. Heinemann LA, Weimann A, Gerken G, Thiel C, Schlaud M, DoMinh T. Modern oral contraceptive use and benign liver tumors: the German Benign Liver Tumor Case-Control Study. Eur J Contracept Reprod Health Care 1998;3:194-200. 
30. Kurahashi H, Takami K, Oue T, Kusafuka T, Okada A, Tawa A, et al. Biallelic inactivation of the APC gene in hepatoblastoma. Cancer Res 1995;55:5007-11.

31. Takayasu H, Horie H, Hiyama E, Matsunaga T, Hayashi Y, Watanabe $\mathrm{Y}$, et al. Frequent deletions and mutations of the beta-catenin gene are associated with overexpression of cyclin $\mathrm{d} 1$ and fibronectin and poorly differentiated histology in childhood hepatoblastoma. Clin Cancer Res 2001;7:901-8.

32. Park WS, Oh RR, Park JY, Kim PJ, Shin MS, Lee JH, et al. Nuclear localization of beta-catenin is an important prognostic factor in hepatoblastoma. J Pathol 2001;193:483-90.

33. Chen TC, Hsieh LL, Ng KF, Jeng LB, Chen MF. Absence of APC gene mutation in the mutation cluster region in hepatocellular carcinoma. Cancer Lett 1998;134:23-8.

34. Marshall B, Isidro G, Boavida MG. Silent APC (adenomatous polyposis coli) gene polymorphism in the Portuguese population. Gene Geogr 1995;9:207-10.
35. Monga SP, Pediaditakis P, Mule K, Stolz DB, Michalopoulos GK. Changes in WNT/beta-catenin pathway during regulated growth in rat liver regeneration. Hepatology 2001;33: 1098-109.

36. Francavilla A, Gavaler JS, Makowka L, Barone M, Mazzaferro V, Ambrosino G, et al. Estradiol and testosterone levels in patients undergoing partial hepatectomy. A possible signal for hepatic regeneration? Dig Dis Sci 1989;34: 818-22.

37. Liddle C, Farrell GC. Role of the oestrogen receptor in liver regeneration in the male rat. J Gastroenterol Hepatol 1993; 8:524-9.

38. Laurent-Puig P, Legoix P, Bluteau O, Belghiti J, Franco $\mathrm{D}$, Binot $\mathrm{F}$, et al. Genetic alterations associated with hepatocellular carcinomas define distinct pathways of hepatocarcinogenesis. Gastroenterology 2001;120:176373.

\section{Book Review}

\section{McManus BM (editor): Atlas of Cardiovascular Pathology for the Clinician, 260 pp, Phila- delphia, Current Medicine, 2000 (\$125.00).}

Last year I was approached by a clinician friend who asked me to recommend a good cardiac pathology book for his residents. I gave him a list of very good books, but still I was not sure that any of those were really appropriate for clinicians. With this new Atlas at hand, I now have no doubts of which book I would recommend if asked the same question again.

This multiauthored Atlas was compiled by Bruce McManus, who assembled a stellar cast of pathologists studying the heart. Like any other pathologist faced with the problem of presenting pathology to clinicians, the editor had to decide what to include and what to delete. I am not sure whether the series editor (Dr. E. Braunwald, who also wrote a Preface), a seasoned clinician, editor, and educator, has helped the pathology crew in this respect, but there is no doubt that the final product will appeal to clinicians. Physically it is very nice, large-format book, published on glossy paper. The topics covered include all the evergreens of cardiac pathology but also quite a bit of basic science data, such as cellular and molecular biology and basic electrophysiology. As one would expect in an Atlas, the emphasis is on visual pre- sentation of data, which are rendered in highquality color photographs. Diagrammatic drawings are yet an important didactic feature of this Atlas. The text that accompanies the illustrations is informative and written in a style that should be readily understandable by non-pathologists. There is a good balance between the length of the text and the number of illustrations. A number of summary tables is included to provide quick information about the most important facts, such as diseases that recur in cardiac allografts or conditions associated with sinus node dysfunction to mention a few. The references are well chosen.

This is a modern pathology Atlas designed to help clinicians understand the pathologic basis of human cardiovascular diseases. It will be widely used by residents and fellows in cardiology, but also by other eager students of medicine. It is an excellent teaching source-a godsend for all of us stuck with giving cardiac pathology lectures to clinical trainees. Above all, it is model on how to present pathology to nonpathologists so that it appears not only relevant and important but exciting and inspiring as well.

Ivan Damjanov

University of Kansas School of Medicine Kansas City, Kansas 